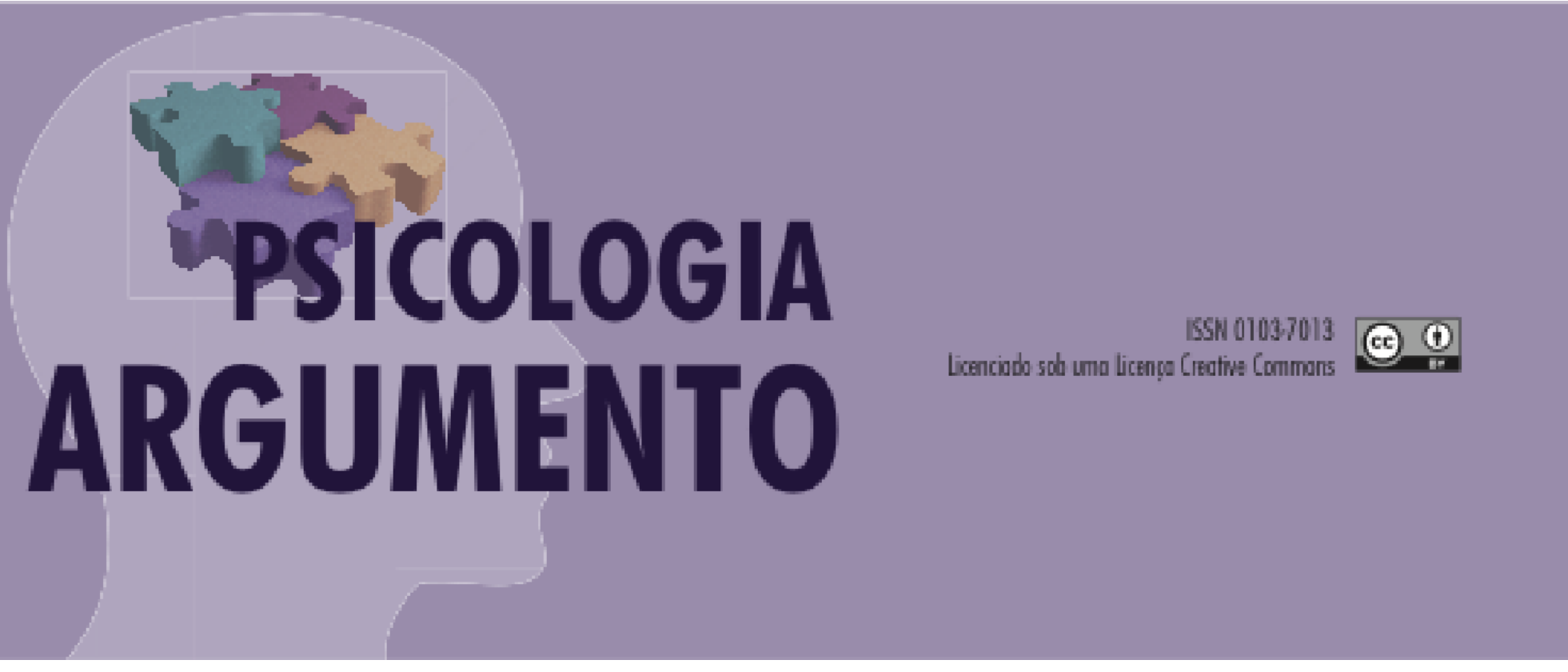

doi: http://dx.doi.org/10.7213/psicolargum.35.89.24226

\title{
Plantas em casa - ter ou não ter? Eis a questão
}

\section{To have or not to have plants? That is the question}

\footnotetext{
Sandra Christina Gressler ${ }^{[a]}$, Danielle Coenga ${ }^{[b]}$

[a] Doutora em Psicologia Social, do trabalho e das Organizações pela Universidade de Brasília, Brasília, DF - Brasil, Professora do Instituto Federal de Mato Grosso do Sul - Campus Ponta Porã, e-mail: sandra.gressler@ifms.edu.br

[b] Mestre em Psicologia Social, do trabalho e das Organizações pela Universidade de Brasília, Brasília, DF - Brasil, Mestre em estudos Internacionais pela University of Montréal, Canadá, e-mail: danicoenga@me.coml
}

\section{Resumo}

A relação do ser humano com a natureza é alvo de estudos com as mais variadas abordagens. Podemos salientar a existência de poucas pesquisas sobre o papel das plantas nos ambientes construídos. Essas questões são importantes uma vez que a cinquenta por cento da população mundial se encontra residindo em cidades, sendo que as atividades diárias como o trabalho, o descanso e a recreação ocorrem primordialmente no ambiente construído. O presente estudo tem como base um questionário com perguntas abertas e fechadas, realizado em um evento público de comemoração ao dia do trabalho $(n=100)$. As análises foram efetuadas, com o auxilio do software EVOC 2000. Foram utilizadas duas questões de evocação que compuseram o estudo, considerando os motivos que levam/levaria as/os participantes a ter plantas e a não ter plantas. Visando conhecer as diferenças e semelhanças das evocações em função das variáveis, os dados foram analisados com o auxílio dos subprogramas SELEVOC e COMPLEX. Os resultados foram cotejados com diferentes explicações teóricas. Em suma, os principais motivos para possuir plantas no ambiente construído estão ligados ao estímulo visual, a qualidade do ar, a percepção das plantas como elementos 
restauradores e a utilidade das plantas. Como os principais motivos para não se possuir plantas são o tempo (gasto e/ou necessário), os cuidados exigidos, o espaço necessário e fatores aversivos como a dengue. Esse estudo exploratório pode contribuir com pesquisas futuras com diferentes abordagens.

Palavras-chave: Plantas; seres humanos; residências; psicologia ambiental

\begin{abstract}
The human relationship with nature, target studies with the most varied approaches. We can emphasize little research about plants in built environments. These issues are important because fifty per cent of the world population is living in cities, and the daily activities such as work, rest and recreation occur primarily in the built environment. These study is based on a questionnaire with open and closed questions and was performed in a public event in celebration of Labor Day $(n=100)$. Analyzes were made using EVOC 2000 software. Two issues of evocation comprised the study, first whereas the reasons that lead/lead the participants to have plants and second the reasons that lead/lead the participants to not have plants. Aiming to know the differences and similarities of pronunciation in function of the variables, the data were analyzed with the aid of the subprograms SELEVOC and COMPLEX. The results were compared with different theoretical explanation. Concluding, the main reasons to have plants in the built environment are linked to the visual stimulus, air quality, the perception of plants as elements restorative and the usefulness of plants. As the main reasons for not have plants are: the time (spent and/or necessary), the care required, the space required and the aversive factors such as dengue. This exploratory study can help with future research with different approaches.
\end{abstract}

Keywords: Plants; humans; housing; environmental psychology

\title{
Resumen
}

La relación del ser humano con la naturaleza es objeto de estudios con los más variados enfoques. Podemos subrayar la existencia de pocas investigaciones sobre el papel de las plantas en los ambientes construidos. Estas cuestiones son importantes ya que el cincuenta por ciento de la población mundial se encuentra residiendo en ciudades, mientras que las actividades diarias como el trabajo, el descanso y la recreación ocurren primordialmente en el ambiente construido. El presente estudio tiene como base un cuestionario con preguntas abiertas $y$ cerradas y fue realizado en un evento público de conmemoración al día del trabajo ( $n=100)$. Los análisis fueron efectuados, con el auxilio del software EVOC 2000. Se utilizaron dos cuestiones de evocación que compusieron el estudio, considerando los motivos que llevaban / llevaba a los participantes a tener plantas ya no tener plantas. Con el fin de conocer las diferencias y similitudes de las evocaciones en función de las variables, los datos fueron analizados con el auxilio de los subprogramas SELEVOC y COMPLEX. Los resultados fueron cotejados con diferentes explicaciones teóricas. En resumen, los principales motivos para poseer plantas en el ambiente construido están ligados al estímulo visual, la calidad del aire, la percepción de las plantas como elementos restauradores y la utilidad de las plantas. Como los principales motivos para no tener plantas son el tiempo (gasto y / o necesario), los cuidados requeridos, el espacio necesario y factores aversivos como el dengue. Este estudio exploratorio puede contribuir con investigaciones futuras con diferentes enfoques.

Palabras clave: Plantas; seres humanos; residencias; psicología ambiental 


\section{Introdução}

Várias áreas do conhecimento buscam investigar e compreender a relação do ser humano com a natureza. Mas o que vem a ser natureza? No dicionário Caldas Aulete da língua portuguesas, o termo natureza é um substantivo feminino que se aplica a todo o mundo material ao redor do homem e no qual ele está inserido, mas independente dele. É definido também como um conjunto composto por seres vivos e seus cenários originais ("idicionário Aulete," n.d.). Ficariam, então, excluídos os cenários construídos das cidades?

A intersecção parece contraditória, se a natureza for pensada como um lugar distante da influência humana e inacessível à maioria da população; assim, teria pouco sentido falar sobre natureza no contexto urbano. Mas natureza é um conceito alusivo, que pode existir e existe mesmo na cidade (Kaplan, 1983).

Segundo algumas abordagens, a preferência humana por ambientes e/ou elementos naturais pode ultrapassar as diferenças individuais. Essas "coincidências" estariam ligadas aos fatores genéticos relacionados à evolução da espécie humana, sendo que outras explicações sugerem o aprendizado social/cultural.

Estudos vinculados às ciências humanas e da saúde enfatizam que a natureza pode apresentar finalidade terapêutica proporcionando efeitos psicológicos e fisiológicos positivos aos seres humanos. Algumas pesquisas (de Kort, Meijnders, Sponselee, \& ljsselsteijn, 2006) indicam que, mesmo um pequeno vislumbre de natureza ou algo que nos lembre a natureza, pode ser benéfico.

Apesar dos avanços em pesquisas relacionadas aos benefícios psicológicos das experiências de contato com a natureza em locais externos, pouco tem sido pesquisado com relação às plantas encontradas no interior de ambientes construídos (Bringslimark, Hartig, \& Patil, 2009). Isso deve refletir a ligação implícita entre "natureza" e "ambiente natural". Essa conexão pode refletir em como as pessoas pensam em ambiente em termos de dimensões básicas de ambiente natural e ambiente construído e ambiente interno e externo.

Quais os fatores envolvidos na relação do ser humano com as plantas encontradas no ambiente doméstico? Podemos compreender a relação do ser humano com a natureza, a partir do comportamento frente às plantas no ambiente doméstico?

O presente estudo tem por objetivo compreender as motivações (justificativas) de se possuir ou não plantas no ambiente doméstico (residencial). As justificativas serão analisadas e cotejadas com explicações encontradas em teorias.

\section{0 ambiente residencial.}

Qual a motivação de estudar as plantas no ambiente doméstico? O espaço residencial apresenta um papel importante, pois é o local de onde se sai e para onde se volta diariamente (Schwarz, Mauksch, \& Rawls, 1995). Os espaços residenciais são psicologicamente centrados em relação ao significado, bem marcados e controlados pelos seus respectivos donos (Sommer, 1973). O 
significado da casa é, entre outros, associado com a expressão própria (Despres, 1991), sendo que as pessoas têm laços fortes principalmente com os objetos e os espaços que se situam dentro e imediatamente em torno de suas casas (Speller, 2005).

Os artefatos no ambiente residencial servem tanto para demarcação física como psicológicas de quem somos, ou de como queremos ser conhecidos. Assim, não é descartada a influência do grupo do qual o indivíduo pertence, pois o grupo pode ditar as normas de comportamento, mesmo quando esse é executado dentro do espaço primário. Sendo que a simbologia dos objetos é confirmada em diferentes culturas e épocas, demonstrando a primazia do uso poético dos símbolos ao invés do uso utilitário (Rapoport, 1969).

Ao considerarmos as plantas no ambiente construído como artefatos, surgem diferentes construtos dentro de um mesmo estudo ou em estudos diversos. Alguns estudos assumem que as plantas são elemento visual que evoca experiências estéticas e mantém a atenção, suportando restauração psicológica. Outros estudos as compreendem como símbolo de natureza e evocam associações com poder independente dos efeitos de estética ou restauração. Suscitando, desta forma, algumas questões que esse estudo visa responder.

\section{Benefícios da relação com a natureza.}

Vinculados às ciências humanas e da saúde, alguns estudos enfatizam a finalidade terapêutica que a relação com a natureza possa promover, com benefícios físicos, mentais e sociais. Estes estudos (landscape therapy; horticulture therapy; therapeutic gardening ou healing garden) destacam, como objeto de pesquisa, os ambientes e paisagens naturais, ou mesmo, os elementos da natureza e/ou o cultivo de plantas em jardins. Uma das abordagens que enfatiza os ambientes e/ou os elementos naturais, como importantes na promoção de bem estar do ser humano, é conhecida por Restorative environmnets ou ambientes restauradores (Alves, 2011; Gressler \& Günther, 2013; Joye \& Van den Berg, 2012). Dentre as teorias que sustentam o conceito de ambientes restauradores, uma foi proposta por Ulrich (1983, 1984; Ulrich et al., 1991) Recuperação Psicofisiológica ao Estresse (Psychophysiological stress recovery).

Segundo a abordagem evolucionista de Ulrich, as experiências de ambientes físicos visualmente prazerosos podem auxiliar na redução do estresse, uma vez que desencadeiam emoções positivas, mantêm o estado de atenção não vigilante, diminuem os pensamentos negativos e possibilitam o retorno à excitação psicológica (physiological arousal) para níveis mais moderados.

Estudos empíricos sobre a relação dos seres humanos com a natureza.

Pressupõe-se que a preferência humana por ambientes naturais possa ultrapassar as diferenças individuais. Essas "coincidências" estariam ligadas aos fatores genéticos relacionados à evolução da espécie humana, enquanto que outras explicações sugerem o aprendizado sociocultural. Dessa maneira, forma-se um conflito entre as explicações biológicas (evolucionistas) e as culturais, para 
justificar a preferência humana por elementos e ambientes naturais (van den Berg, 1999).

A sugestão mais conhecida de explicação biológica evolucionista é proposta pelo biólogo Wilson (1984), na teoria conhecida por biofilia propõem a existência de um componente genético humano que define a afiliação inevitável dos seres humanos com outros organismos vivos. Kellert (1993) por sua vez sugere uma gama de expressões físicas, emocionais e intelectuais da tendência da associação genética (biofilia) do ser humano à natureza. O autor utiliza uma tipologia de valores para investigar algumas possibilidades, são eles:

a) Valor utilitário: Esse valor enfatiza os benefícios materiais que os humanos extraem da exploração da natureza para satisfazer suas necessidades e desejos.

b) Valor negativista: Tem como função a segurança e a proteção em que são enfatizados os sentimentos de aversão, de medo, o não gostar da natureza e a alienação à natureza.

c) Valor dominador: Enfatiza-se o desejo de controlar, de dominar, de subjugar a natureza.

d) Valor naturalístico: Tem como função o desenvolvimento mental e físico, a habilidade em lidar com ambientes externos e a curiosidade. Enfatiza-se a satisfação que as pessoas obtêm da experiência direta com a natureza e com a vida selvagem.

e) Valor ecológico-científico: Tem como função a habilidade de observação, o conhecimento e entendimento. Enfatiza-se o estudo sistemático do padrão biofísico, a estrutura e as funções da natureza.

f) Valor estético: Possui como função a inspiração, a harmonia, a paz e a segurança. Enfatiza-se, antes de qualquer coisa, a resposta emocional de intenso prazer com a beleza física da natureza.

g) Valor simbólico: É enfatizada, aqui, a tendência dos humanos em usar a natureza para comunicação e meditação.

h) Valor humanístico: Enfatiza-se a capacidade dos humanos em cuidar de, e de se tornarem próximos aos animais.

i) Valor moralista: Têm por função manter a ordem e o significado na vida, laços de afiliação e proximidade. É enfatizado o certo ou errado dirigido ao mundo não humano, uma forte afiliação, relevância espiritual e preocupação ética com relação à natureza.

Alguns fatores, no entanto, ainda necessitam de respostas no que se refere à hipótese biofilia e são sugeridos por Kahn (1997) ao indagar: Como podemos contestar a biofilia, se ela está baseada em questões genéticas? Pode a hipótese de a biofilia ser refutada?

$\mathrm{Na}$ tentativa de resolver o conflito entre as justificativas biológicas e culturais, Bourassa $(1988,1990)$ e Hartig (1993) trabalham em prol de uma teoria integrativa. De acordo com Bourassa (1990) ambos os fatores correspondem a diferentes modelos de percepção, coexistentes. Segundo Hartig (1993) os fatores biológicos e culturais são diferentes mecanismos na adaptação coletiva e refletem a gradual transição das condições de vida natural para as feitas pelo homem (van den Berg, 1999). 
As teorias apoiadas nos aspectos culturais buscam explicar a relação do ser humano com a natureza ao investigar as crenças, os valores, as atitudes e as normas envolvidas nessa relação. Para Buijs, Elands, e Langers (2009) a imagem que se tem da natureza é uma imagem cognitiva, a priori, de experiências com a natureza e de discursos sobre ela. Os autores reforçam que essa imagem é influenciada pela cultura, pelas crenças e por valores normativos.

Os estudos que visam compreender os valores que possam explicar atitudes e comportamentos ambientais (Karp, 1996; Stern, Dietz, Abel, Guagnano, \& Kalof, 1999), sugerem orientação de valores - egoísta, socioaltruísta e biosférico.

Aparentemente, os valores biosféricos deveriam ser mais importantes do que os valores altruístas, para estimular comportamentos pró-ambientais. No entanto, alguns estudos mostraram não ser possível distinguir, empiricamente, esses dois valores (de Groot \& Steg, 2010; Steg, Dreijerink, \& Abrahamse, 2005).

Estudos que investigam o construto atitude (Milfont, 2007) destacam a existência de duas linhas relacionadas às atitudes ambientais. A primeira se volta para os interesses e motivos pessoais para lidar com as questões ambientais e, a segunda enfatiza os motivos pró-sociais com a ativação da norma e os valores humanos (Milfont, 2007). Para Thompson e Barton (1994), a atitude antropocêntrica é caracterizada pelo interesse em manter a qualidade de vida, a saúde e a existência da espécie humana. Para isso, faz-se necessário preservar os recursos naturais e o ecossistema. Dessa forma, cria-se uma relação de troca, em que o homem preserva a natureza para seu benefício. Existe, assim, uma base motivacional. Já na atitude ecocêntrica, a natureza é considerada uma dimensão espiritual e de valor intrínseco, refletida nas experiências humanas relacionadas aos sentimentos sobre o ambiente natural. Acredita-se que no ecocentrismo o homem está conectado à natureza e a valoriza por si mesma (Coelho, Gouveia, \& Milfont, 2006). Assim, as atitudes antropocêntricas e ecocêntricas se diferenciam quanto aos motivos da preocupação e do interesse ambiental (Thompson \& Barton, 1994). Dessa maneira, uma conceituação geral na distinção entre o "ser parte" da natureza versus o "ser aparte" da natureza, por si só, não agrega determinantes de uma posição clara com relação ao ambiente natural.

Para Lima (2006) atitude é apenas um entre vários fatores importantes na predição de comportamento. De acordo com Castro (2005), "o que parece diferenciar hoje as pessoas são menos as suas crenças em relação ao ambiente e mais os seus comportamentos" (p.183). Desta forma, um estudo que vise compreender o comportamento parece ser uma alternativa viável para a questão da relação do ser humano com a natureza.

\section{O comportamento humano.}

Para Stern (2000), o primeiro passo para compreender a complexidade de um comportamento é aprimorar a perspectiva de que esse é uma função do organismo e seu ambiente. Para o autor, as normas pessoais exercem influência nos comportamentos, sendo que o comportamento é um produto interativo do compartilhamento pessoal de variáveis atitudinais e de fatores contextuais (Stern, 2000). 
Essa formulação da teoria comportamento - atitude - contexto, implica que, para comportamentos pessoais que não são fortemente favoráveis pelo contexto, mais difícil, com maior consumo de tempo, ou por ser um comportamento mais custoso, mais fraco é sua dependência nos fatores atitudinais (Stern, 2000). Isso é: a associação comportamento-atitude é mais forte quando fatores contextuais são neutros. São nulas as abordagens, quando forças contextuais são fortemente positivas ou negativas, efetivamente obrigando ou proibindo o comportamento em questão.

Dessa forma, são enumeradas, variáveis causais que possam determinar o comportamento ambiental, sendo estas: a) Fatores atitudinais; b) Fatores contextuais; c) Capacidade pessoal; d) Hábito ou rotina.

1. Fatores atitudinais - normas, crenças e valores. Indica a predisposição específica para um comportamento (normas morais pessoais específicas em termos de teoria da ativação da norma, atitudes em termos da teoria do comportamento planejado) e comportamento específico de crenças - sobre a dificuldade de fazer certas ações ou a respeito de suas consequências para o self, os outros ou o ambiente). Várias teorias da psicologia social, incluindo teoria da dissonância cognitiva, teoria da ativação da norma e teoria do comportamento planejado, têm mostrado variâncias em comportamentos pró-ambientais específicos. Essas pesquisas têm demonstrado que comportamento pró-ambiental pode ser afetado pelo comprometimento pessoal e o custo pessoal percebido e benefícios de ações em particular, bem como crenças de comportamento específico e normas pessoais.

2. Fatores contextuais - o segundo maior tipo de variável casual é externa ou fatores contextuais. Isso inclui a influência interpessoal; a propaganda; as regulamentações do governo; outros fatores legais e institucionais; os incentivos monetários e os custos; as dificuldades físicas de ações específicas; a capacidade e a pressão devido à tecnologia e o ambiente construído. $O$ fator contextual pode ter diferentes significados para pessoas com diferentes atitudes ou crenças. Por exemplo, o preço mais elevado do produto "orgânico" pode ser um obstáculo econômico para algumas pessoas comprarem, enquanto que para outros pode representar um produto superior de mercado.

3. Capacidade pessoal - é o terceiro tipo de variável casual. Inclui as competências necessárias para uma ação em particular, a capacidade geral e os recursos como letramento, dinheiro, status social, e poder. Embora essas variáveis tenham limitado poder de explicação para muitos comportamentos ambientalmente significantes, elas podem ser importantes para comportamentos que dependem fortemente de uma capacitação específica.

4. Hábito ou rotina - é um caso distinto de variável causal. A mudança de comportamento geralmente exige a quebra de hábitos e se torne estabelecida na criação de novos hábitos. Hábito é a forma de processos padrão de funcionamento.

As evidências sugerem que diferentes tipos de variáveis casuais são importantes, para cada comportamento em particular. A proposta comportamento - atitude - contexto, que os diferentes tipos de fatores casuais podem interagir, 
implica que, interpretações baseadas apenas nos efeitos principais podem ser seriamente equivocadas. Estudos que examinam apenas fatores atitudinais são muito prováveis de encontrar inconsistência, devido aos efeitos serem dependentes em aptidão e contexto. Similarmente, estudos que examinam apenas variáveis contextuais, podem encontrar algumas respostas, mas podem falhar em revelar sua dependência em atitudes e crenças individuais(Stern, 2000).

A teoria proposta por Stern (2000) para explicar o comportamento ambiental não ativista, parece um bom suporte para pesquisas que visem questionar a tendência comportamental para realização de determinadas ações. Podendo ser amplamente utilizada para a compreensão do comportamento frente às plantas.

\section{Objetivo e critérios de elegibilidade.}

A relação do ser humano com a natureza é alvo de diversos estudos com as mais variadas abordagens. Pesquisar os fatores motivadores de se possuir ou não plantas no ambiente residencial pode facilitar a compreensão da relação dos seres humanos com as plantas/natureza, uma vez que o ambiente residencial - ambiente primário - possibilita o controle e a expressão de ser. Essas questões se tornam importantes ao analisarmos que as atividades diárias como o trabalho, o descanso e a recreação ocorrem primordialmente no ambiente construído (Schultz, 2002), a população adulta, fora o tempo que gasta se deslocando de uma construção a outra, passa pouco tempo no ambiente externo (Robinson e Silvers, 2000 citado em Schultz, 2002), além do fato de atualmente, cinquenta por cento da população mundial se encontra residindo em centros urbanos (United Nations, 2008). Dessa forma esse estudo exploratório tem por objetivo compreender os motivos envolvidos no comportamento humano frente às plantas no ambiente residencial.

\section{Método}

O estudo foi realizado em Brasília- DF. A coleta de dados ocorreu no dia primeiro de maio durante um evento público comemorativo ao dia do trabalhador. O objetivo desse estudo foi obter as justificativas e consequentemente os fatores relacionados ao comportamento de se possuir e/ou cuidar de plantas. Um questionário com questões abertas e fechadas foi elaborado para esse estudo. A primeira questão foi: Escreva cinco motivos que leva (levaria) você a ter plantas em sua residência (casa, apartamento, quitinete, etc.). A segunda questão foi: Escreva cinco motivos que leva (levaria) você a não ter plantas em sua residência, (casa, apartamento, quitinete, etc.), as questões seguintes referem-se a dados demográficos, além de questões relacionadas à posse ou não de plantas e a questão de ser ou não o responsável pelos cuidados com as plantas no ambiente residencial.

Munida com cinco pranchetas, canetas e cópias do instrumento, a pesquisadora abordou possíveis participantes (com idade aparentemente superior a quinze anos), explicando o propósito e a livre escolha na participação. 
Análise.

Foi realizada análise estatística básica descritiva indutiva, com os dados sócio-demográficos e análise qualitativa das informações, com o auxílio do software EVOC 2000. Utilizaram-se as duas questões de evocação que compuseram o estudo, considerando os motivos que levam/levariam as/os participantes a ter plantas e a não ter plantas. Essas respostas foram organizadas com base nas variáveis: número de identificação dos sujeitos, local de moradia (apartamento ou casa); e posse de plantas (tem plantas ou não tem plantas). Este material foi formatado (retirando-se caracteres especiais e a acentuação das palavras) e salvo com a extensão CVC (separado por vírgulas), de modo a compor dois corpus de análise: 1) Corpus "ter plantas" e 2) Corpus "não ter plantas". Para ambos os corpus foram conservados todos os dados de identificação dos sujeitos.

A fim de conhecer o que as/os participantes pensam sobre possuir ou não plantas, cada corpus foi submetido a análises por meio dos subprogramas RANGMOT e RANGFRQ. A lista do contexto de uso das palavras, fornecida pelo LISTVOC, foi utilizada como base para apresentar os possíveis modos de interpretar os resultados advindos dessas análises. Em seguida, visando conhecer as diferenças e semelhanças das evocações em função das variáveis (posse e tipo de residência), os dados foram analisados com o auxílio dos subprogramas SELEVOC e COMPLEX.

\section{Resultados}

Estatística básica descritiva indutiva - contagem de frequência. Constatouse que, do total de respondentes ( $n=100), 65$ informaram residir em casa; 26 em apartamento; cinco em quitinete. A idade média dos sujeitos foi de 33 anos, sendo a moda 32 anos. Do total de respondentes $(n=100), 60$ respondentes são do sexo feminino, 38 do sexo masculino e dois questionários deixaram o campo sexo em branco. Entre os respondentes, 75 possuem plantas em casa, desses, 60 afirmam ser responsáveis pelos cuidados com as plantas ( $80 \%$ dos que possuem plantas).

Apesar de pedir aos participantes da pesquisa para listar cinco motivos em duas perguntas, apenas 16 questionários completaram totalmente esses espaços de resposta. Das mil respostas possíveis, 500 para cada pergunta $(n=100)$, foram obtidas 369 respostas para os motivos de se ter plantas e 244 respostas para os motivos para não possuir plantas. Esses dados poderiam ter sido significativos se houvesse a alteração aleatória da ordenação dessas duas questões. Esse procedimento deverá ser observado na possível replicação deste estudo.

EVOC - A seguir, serão apresentados os resultados das análises efetuadas com o corpus "ter plantas" e, posteriormente, às realizada a partir do corpus "não ter plantas".

A) Resultado do Corpus "ter plantas". Esse corpus refere-se a todas as respostas coletadas para a questão "Motivos que levam ou levariam você a possuir plantas". Foi composto por 1011 palavras, sendo 362 palavras diferentes. A partir do resultado fornecido pelo RANGMOT (ordem média, frequência mínima e frequência intermediária) foi possível efetuar a análise dos dados por meio do 
RANGFRQ. Considerando a ordem media de 2.8, a frequência mínima 6 e a frequência intermediária 13 , os resultados dessa análise são apresentados na Tabela 1.

\section{Tabela 1}

Estrutura do corpus "ter plantas", frequência e ordem média de evocação

\begin{tabular}{|c|c|c|c|}
\hline & TER PLANTAS & $\boldsymbol{F}$ & OME \\
\hline \multirow{7}{*}{$\begin{array}{l}\text { ELEMENTOS } \\
\text { CENTRAIS }\end{array}$} & AMBIENTE & 51 & 2,51 \\
\hline & MAIS & 31 & 2,58 \\
\hline & NATUREZA & 28 & 2,64 \\
\hline & CASA & 23 & 2,26 \\
\hline & BELEZA & 22 & 1,73 \\
\hline & DECORAÇÃO & 16 & 1,94 \\
\hline & BONITO & 13 & 2,15 \\
\hline \multirow{20}{*}{$\begin{array}{l}\text { ELEMENTOS } \\
\text { PERIFÉRICOS }\end{array}$} & PLANTAS & 33 & 2,85 \\
\hline & PARA & 27 & 2,81 \\
\hline & COM & 21 & 3,00 \\
\hline & GOSTO & 12 & 2,42 \\
\hline & ORNAMENTAÇÃO & 11 & 1,82 \\
\hline & DEIXA & 11 & 2,54 \\
\hline & PORQUE & 10 & 2,40 \\
\hline & PELA & 10 & 2,60 \\
\hline & MUITO & 9 & 2,67 \\
\hline & TRAZ & 9 & 2,67 \\
\hline & PURO & 9 & 2,78 \\
\hline & AGRADÁVEL & 8 & 2,37 \\
\hline & MEIO & 8 & 2,50 \\
\hline & FICA & 8 & 2,62 \\
\hline & BEM & 7 & 2,71 \\
\hline & VERDE & 7 & 2,71 \\
\hline & MELHORA & 6 & 1,83 \\
\hline & CONTATO & 6 & 2,17 \\
\hline & HARMONIA & 6 & 2,67 \\
\hline & NÃO & 6 & 2,26 \\
\hline \multirow{6}{*}{$\begin{array}{l}\text { ELEMENTOS } \\
\text { RESIDUAIS }\end{array}$} & TERAPIA & 11 & 4,00 \\
\hline & PLANTA & 9 & 3,22 \\
\hline & VIDA & 8 & 3,50 \\
\hline & POR & 7 & 3,00 \\
\hline & QUALIDADE & 7 & 3,00 \\
\hline & EMBELEZA & 7 & 3,29 \\
\hline
\end{tabular}

B) Resultado do Corpus "não ter plantas". O corpus referente às evocações ao estímulo "não ter plantas" refere-se a todas as respostas coletadas para a questão "Motivos que levam ou levariam você a não possuir plantas". Foi composto por um total de 816 palavras, dessas 298 palavras diferentes. Por meio dos dados fornecidos pelo RANGMOT (ordem média, frequência mínima e frequência intermediária) foi possível efetuar a análise com o RANGFRQ. 
Considerando a ordem média de 2.3, a frequência mínima 4 e a frequência intermediária 11, os resultados dessa análise são apresentados na Tabela 2.

\section{Tabela 2}

Estrutura do corpus "não ter plantas", frequência e ordem média das evocações

\begin{tabular}{|c|c|c|c|}
\hline & NÃO TER PLANTAS & $f$ & OME \\
\hline ELEMENTOS & NẪO & 50 & 2,00 \\
\hline \multirow[t]{8}{*}{ CENTRAIS } & CUIDAR & 41 & 1,93 \\
\hline & TEMPO & 38 & 1,79 \\
\hline & PLANTAS & 20 & 2,15 \\
\hline & TER & 18 & 2,00 \\
\hline & TENHO & 14 & 1,57 \\
\hline & DENGUE & 12 & 1,67 \\
\hline & TRABALHO & 11 & 2,09 \\
\hline & NÃO & 29 & 2,00 \\
\hline ELEMENTOS & FALTA & 29 & 2,48 \\
\hline \multirow{12}{*}{ PERIFÉRICOS } & ESPACO & 27 & 2,48 \\
\hline & MUITO & 11 & 2,45 \\
\hline & SUJEIRA & 11 & 2,64 \\
\hline & CUIDADO & 10 & 2,00 \\
\hline & TEM & 10 & 2,20 \\
\hline & AGUA & 8 & 2,12 \\
\hline & INSETOS & 7 & 2,29 \\
\hline & PORQUE & 5 & 1,00 \\
\hline & MOSQUITO & 5 & 1,80 \\
\hline & AMBIENTE & 5 & 2,00 \\
\hline & PEQUENO & 4 & 2,00 \\
\hline & VENENOSAS & 4 & 2,25 \\
\hline ELEMENTOS & POR & 10 & 2,90 \\
\hline \multirow[t]{6}{*}{ RESIDUAIS } & ALGUMAS & 7 & 2,43 \\
\hline & CASA & 7 & 2,43 \\
\hline & CRIANCAS & 7 & 3,29 \\
\hline & RISCO & 6 & 2,33 \\
\hline & SEM & 5 & 2,80 \\
\hline & MUITA & 4 & 4,00 \\
\hline
\end{tabular}

A influência das variáveis, Corpus "ter plantas" e "não ter plantas". Para conhecer a influência das variáveis sobre as respostas dos sujeitos, este corpus foi submetido à análise por meio dos subprogramas SELEVOC e COMPLEX. Após o primeiro separar o corpus em função das diferentes modalidades das variáveis, - COMPLEX possibilita o cruzamento dessas informações - vale salientar que este cruzamento se dá apenas entre duas modalidades de variáveis, por vez. Assim, o resultado deste cruzamento apresenta: (1) uma lista de palavras presentes unicamente no primeiro arquivo (relativo a uma modalidade da variável); (2) uma lista de palavras presentes exclusivamente no segundo arquivo (referente à outra modalidade); (3) as palavras (e suas respectivas frequências) comuns aos dois arquivos; e (4) uma lista de comparação das especificidades das palavras com frequência maior que cinco em ambos os arquivos.

Os resultados de cada uma dessas análises em função das variáveis: POSSE e MORADIA são apresentadas respectivamente na Tabela 3 (posse) e Tabela 4 (moradia). 


\section{Tabela 3}

Palavras comuns vinculadas as respostas para as justificativas de "ter plantas" e "não ter plantas" com frequência maior que cinco. Palavras evocadas para variável POSSE

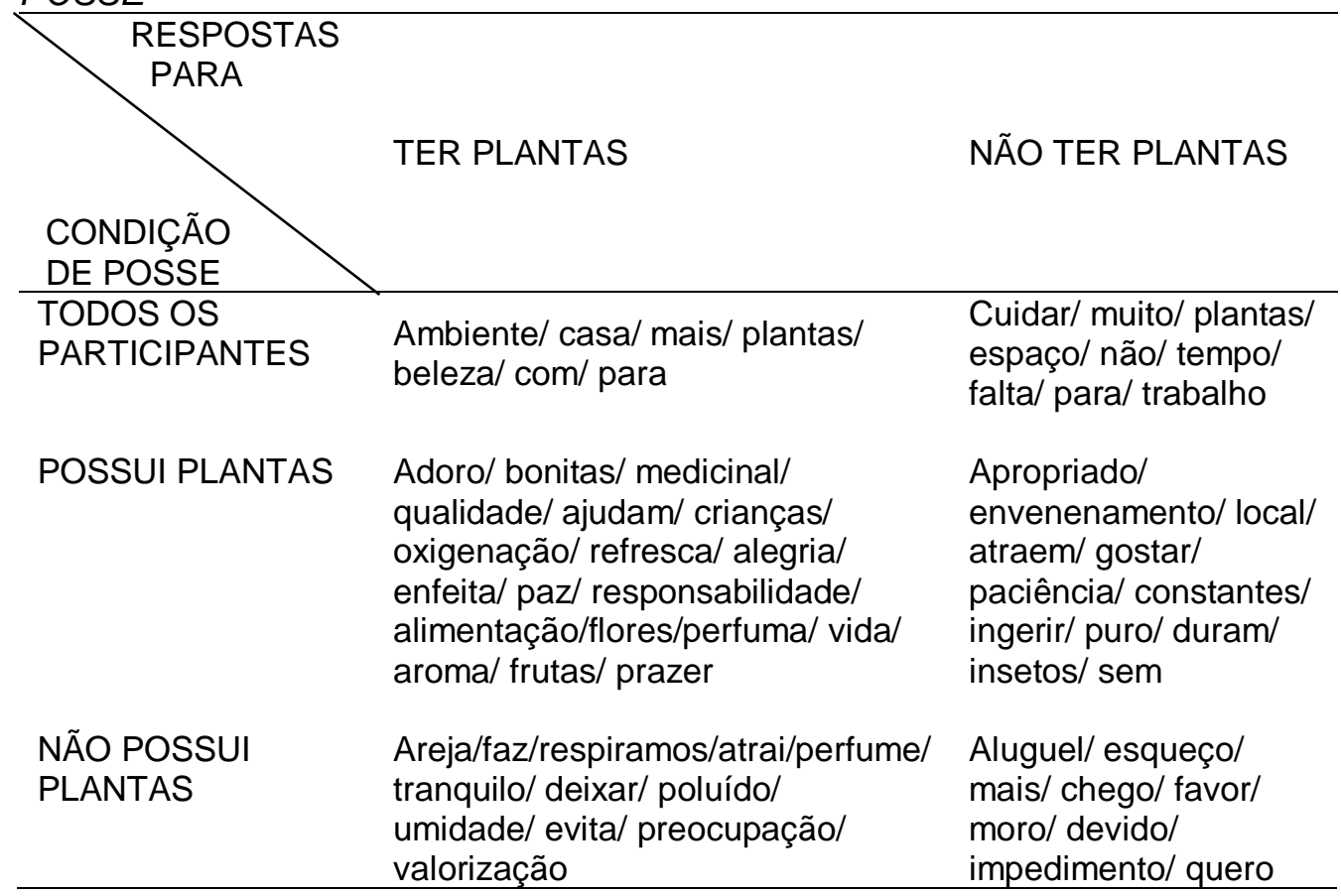

\section{Tabela 4}

Palavras comuns vinculadas as respostas para as justificativas de "ter plantas" e "não ter plantas" com frequência maior que cinco. Palavras evocadas para variável MORADIA

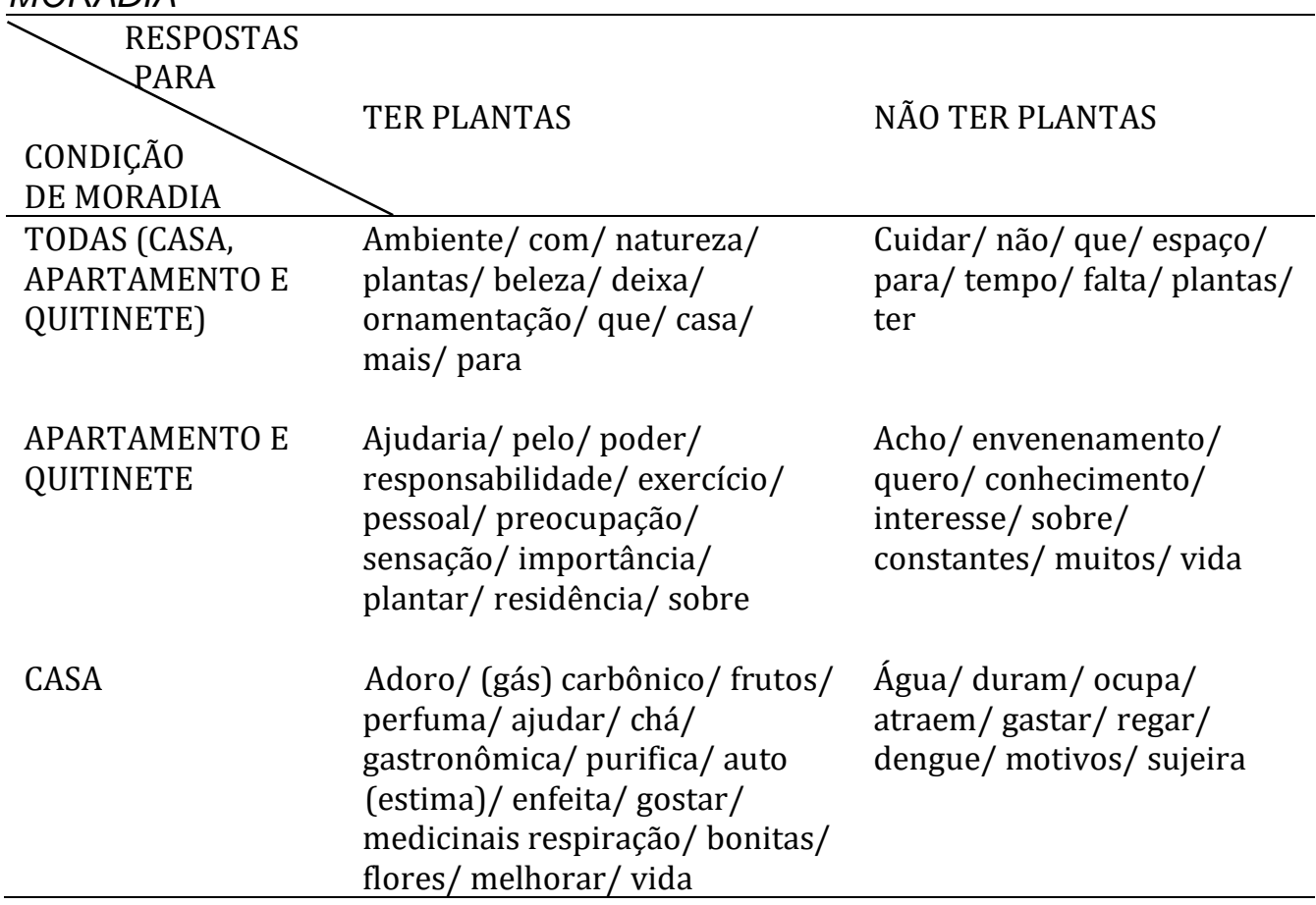




\section{Discussão}

Em respostas para a pergunta "os motivos que leva/levariam você a possuir plantas", da forma como a pergunta foi elaborada, as/os participantes remetem "ter plantas", imediatamente (elementos centrais das evocações $f \geq 13$ e $M<2.8$ ), ao local (ambiente, casa, apartamento, lugar) e às questões ligadas ao fator estético, decorativo (decoração, bonito). Surgem também questões que relacionam o desejo de proximidade com a natureza. Dentre os elementos periféricos acerca do "ter plantas" ( $f \geq 13$ e $M \geq 2.8 / f<13$ e $M<2.8$ ) as palavras agradável e melhora, evocam as sensações de um ambiente agradável, que pode ser compreendido de duas maneiras: a) como o bem-estar que as plantas, o verde, traz(em ), b) e de forma mais abrangente, relacionada ao meio ambiente e os benefícios relacionados à melhoria (melhora) da qualidade do ar (puro). Os elementos residuais ( $f<13$ e $M \geq 2.8$ ), por sua vez, apresentam o "ter plantas" como uma terapia, e a percepção das plantas como seres vivos, ou seja, que possuem vida.

É possível observar que questões ligadas aos estímulos visuais como decoração, beleza, bonito, ornamentação e embeleza são encontrados como elementos centrais, periféricos e residuais nas evocações.

Resposta para a questão "os motivos que leva/levariam você a não ter plantas". Os elementos centrais e, portanto, mais relevantes ( $f \geq 11$ e $M<2.3$ ), para o "não ter plantas" concentram-se nas palavras não e cuidar e apresentam um ponto interessante trazido pelo verbo ter, por meio do qual as pessoas ressaltam não possuir os requisitos ideais para cuidar de plantas como não ter tempo para cuidar, que o trabalho cuidar de plantas exige, podendo assim ser compreendido como uma justificativa / ou motivo para não possuir plantas. Surge também que, caso as plantas não sejam cuidadas adequadamente corre-se o risco da proliferação do mosquito transmissor da dengue.

Dentre os elementos periféricos ( $f \geq 11$ e $M \geq 2.3 / f<11$ e $M<2.3$ ), estão as palavras que, de certo modo, dão sentido aos elementos centrais, mas que, principalmente, correspondem a outros elementos importantes para pensar a posse de plantas. Aqui a justificativa de "não ter plantas" está vinculado também à falta de espaço. Surgem palavras ligadas aos riscos que as plantas trazem - de 
acumular água parada, atrair / propiciar a proliferação de insetos e mosquitos e o fato de algumas plantas serem venenosas. Também aparece a questão do cultivo de plantas relacionada à sujeira (folhas, terra, água - molhar) trazida para o ambiente (casa, apartamento).

Por fim, os elementos residuais ( $f<11$ e $M \geq 2.3$ ) veem como um reforço para as justificativas mais importantes, nesse caso aparecem que algumas plantas podem colocar em risco a saúde das crianças.

\section{Corpus e a influência das variáveis.}

Utilizando dos subprogramas SELEVOC e COMPLEX, foram feitas análises para conhecer a influência das variáveis POSSE e MORADIA sobre as respostas dos sujeitos.

Análise da variável POSSE (ter ou não ter plantas). Interessante nessa análise é observar as respostas dos participantes que possuem plantas e, assim, suas motivações para esse comportamento, bem como as respostas dos participantes que não possuem plantas e suas possíveis motivações para esse comportamento.

No caso dos respondentes que possuem plantas, suas motivações estão relacionadas aos valores, atitudes e normas sociais representado na palavra adoro e no prazer em possuir plantas, sugerindo o desejo de transmitir esses valores para as crianças, ensinando-as sobre a responsabilidade com a vida de outros seres vivos. Essas questões são apoiadas pelo fator restaurativo das plantas de transmitir paz, alegria, sublinhado, ainda, os estímulos visuais e olfativos por elas proporcionados - são bonitas, possuem flores e enfeitam, perfumam e trazem aroma para o ambiente. Surge também a utilidade das plantas - alimentação saudável, frutas frescas e uso medicinal.

As pessoas que não possuem plantas, e suas respostas que sugerem os motivos de não possuí-las, apresentam uma particularidade interessante ao ser observado a presença de verbos conjugados na primeira pessoa do singular, de modo que é possível afirmar que estas/es respondentes se colocam de modo a explicar o porquê de não possuírem plantas. Dentre os motivos esses participantes ressaltam que não querem plantas, moram de aluguel ou de favor, que chegam tarde (passam pouco tempo no ambiente residencial), esquecem de cuidar, e que o cuidado com as plantas poderiam representar impedimento para viagens.

Já as/os participantes que possuem plantas sugerem que seria motivo para não ter plantas caso não existisse em suas residências um local apropriado - com relação à luminosidade; caso não tivessem paciência ou não gostassem de plantas; ou mesmo se a rotina exigisse períodos constantes de ausência que não permitisse o cuidado das mesmas. Questões referentes ao desconhecimento dos cuidados necessários para evitar a proliferação do mosquito da dengue também foram levantadas como um fator que os levaria a não ter plantas. 
Os participantes que não possuem plantas responderam que, o motivo que os levaria a ter plantas no ambiente doméstico advém das preocupações relacionadas ao meio ambiente, como a qualidade do ar.

Análise da variável MORADIA (quitinete, apartamento e casa). Segundo Stern (2000) os fatores contextuais são capaz de influenciar o comportamento. Nesse sentido investigamos se a escolha da moradia (casa ou apartamento/quitinete) seria capaz de influenciar na presença de plantas no ambiente residencial. Analisando as respostas dos residentes de quitinete, apartamento e casa, para a pergunta possuir plantas, se assemelha muito as respostas descritas no corpus possuir plantas. São mencionadas a beleza das plantas assim como as questões relacionadas à decoração do lugar (casa, apartamento/quitinete), a busca pela proximidade com a natureza e também a questões relacionadas a qualidade do ar que respiramos. Da mesma forma como as respostas gerais dos participantes para não possuir plantas está ligada a falta de espaço e tempo para cuidar ou ter plantas no ambiente doméstico.

Apartamento e quitinete - Analisando as respostas comuns com as justificativas de possuir plantas, apenas ao grupo de participantes que reside em apartamento/quitinete verificou-se que esses percebem a importância a responsabilidade e preocupação que existe no exercício de cultivar (plantar), cuidar das plantas naquele ambiente (residência). Listando quais seriam os motivos para não possuir plantas, esses respondentes, evocam palavras relacionadas a questão das plantas como ser vivo (vida) que exige cuidados constantes sendo necessário conhecimento e interesse para poder cuidar delas.

É importante ressaltar que os respondentes na modalidade apartamento/quitinete não abordam, especificamente, os temas de decoração e beleza das plantas - diferente da influência geral da variável moradia. Por outro lado, as evocações sobre o "ter plantas" de pessoas que habitam apartamentos/quitinetes está relacionada ao exercício do cuidado, responsabilidade e preocupação. Sugere-se que isso está relacionado ao fato de que plantas em apartamentos, em sua maioria, se encontra em floreiras ou vasos e necessitam de cuidados diferentes das plantas localizadas em canteiros nos jardins das casas.

Casa - As/os participantes que residem em casa, ao listar os motivos para possuir plantas evocam palavras relacionadas a fatores atitudinais adoro e gostar de possuir plantas, associadas à apreciação estética e olfativa (enfeita, bonita e perfuma). As plantas são percebidas como seres vivos (vida) em seu processo de crescimento e mudança - das flores aos frutos. Aparecem também questões ligadas à utilidade das plantas para o consumo humano como em chás medicinais, frutas e verduras (gastronômica). Partilham também vocabulário que indica algumas questões mais amplas relacionadas ao comportamento pró-ambiental e a preocupação com a qualidade do ar que respiramos (purifica, gás carbônico) e a questão ligada à restauração (melhorar a vida).

As justificativas para não possuir plantas mesmo residindo em uma casa são relacionadas à necessidade de regar as plantas, nesse sentido existem justificativas pró-ambientais de reduzir o consumo de água (gastar), ou mesmo 
justificativas relacionadas a proliferação do mosquito da dengue (atraem) e/ou relacionadas a "molhadeira" (sujeira) provocada com ao regar as plantas.

Como pode ser observado, por meio das questões de evocação aos estímulos "ter plantas" e "não ter plantas", as/os participantes da pesquisa forneceram dados que permitem investigar as justificativas e comportamentos relacionados à posse ou não de plantas no ambiente doméstico.

As respostas vão ao encontro da literatura supracitada, sendo que para as questões ligadas a posse e cuidados ou mesmo a intenção de posse de plantas, podemos salientar a teoria sugerida por Stern (2000). O autor menciona que o comportamento é resultante do fator atitudinal (valores, normas e atitude), contextual, da capacidade pessoal e do hábito e rotina. Assim para as/os participantes que possuem uma atitude positiva com relação às plantas, os fatores contextuais que poderiam parecer obstáculos - a proliferação do mosquito da dengue, a falta de espaço, a necessidade de cuidados constantes - são superados. Por outro lado os respondentes que não possuem uma atitude positiva com relação às plantas, esses fatores se tornam obstáculos para realização desse comportamento em específico. Nesse sentido as questões da capacidade pessoal e do hábito também contribuem para o comportamento de não possuir plantas.

Dentre os respondentes que possuem plantas são encontradas como mais frequência respostas ligadas aos valores estético (beleza, decoração), utilitário (chás, frutas, temperos e verduras), humanístico (respeitar e cuidar de um ser vivo), simbólico (e a proximidade com a natureza) e moralista (ensinar o cuidar das plantas para outras gerações) sugeridos por Kellert (1993). Sugerido por Ulrich et al. (1991) percebe-se as questões de restauração por meio da visão de ambientes prazerosos (bonitos, decorados) que proporcionam um ambiente calmo, tranquilo que transmite paz, adequado para uma terapia. Sugerida por Thompson e Barton (1994) aparece a atitude antropocêntrica ligada a preocupação com a qualidade do ar que respiramos.

Dentre os respondentes que não possuem plantas, percebe-se a questão dos fatores contextuais, do hábito ou rotina e da capacidade pessoal como sugerido por Stern (2000) se sobressaem (falta de tempo para cuidar, falta de espaço, não gostar e não saber cuidar). No entanto, o valor negativista (aversão) proposto por Kellert (1993) também se faz presente, como plantas venenosas que poderiam ser nociva às crianças, as questões da dengue, sujeira e insetos.

\section{Considerações finais}

Considerando-se todas as respostas obtidas é possível observar uma nítida divisão entre os motivos para possuir plantas no ambiente residencial e o motivo para não possuí-las. Listados como os motivos para possuir plantas estão às questões ligadas ao estímulo visual (beleza das plantas, decoração do espaço); à qualidade do ar (umidade, oxigênio, menos poluição); à percepção das plantas como elementos restauradores (paz, tranquilidade e bem estar); à utilidade das plantas (chás, temperos, frutas, verduras, sombra); proximidade com a natureza; questões pró-ambientais (preservação da natureza, cuidado com o meio ambiente, 
qualidade do ar); plantas como ser vivo (nasce, cresce, e necessita de cuidados); e ao estímulo olfativo.

Mencionados como os motivos para não possuir plantas são o tempo (gasto e/ou necessário); os cuidados exigidos; o espaço; fatores de aversão (a proliferação do mosquito da dengue, a sujeira - terra, folhas, água, e possíveis perigos como o de plantas venenosas e/ou pessoas alérgicas); surge também à atribuição a outras pessoas e/ou animais que impeçam o cultivo de plantas; e passar muito tempo ausente do ambiente residencial em consequência da rotina diária.

Questões que aparecem em ambas as justificativas (possuir e não possuir plantas) são relacionadas principalmente aos valores, atitudes e normas sociais (positivos: meu pai teve um orquidário, meu marido e minha mãe gostam, meus filhos gostam, nasci e cresci com plantas em casa, porque eu gosto, não tenho motivos para não ter; negativos: eu não gosto, sei que é importante mais não quero ter, descaso, desinteresse, prefiro um livro); à percepção das plantas como seres vivos (que alegram, mas ao mesmo tempo exigem responsabilidade); e a questões ambientais como preservação da natureza, mas ao mesmo tempo o desperdício de água para regá-las.

Por fim, vale ressaltar que o presente estudo tem caráter exploratório, sendo sugerida para futuras investigações a elaboração de um modelo que correlacione esses fatores. Dessa maneira, será possível apresentar soluções para estratégias ligadas ao bem estar da população urbana.

\section{Referências}

Alves, S. M. (2011). Ambientes restauradores. In S. Cavalcante \& G. A. Elali (Eds.), Temas básicos em psicologia ambiental (pp. 44 - 52). Rio de Janeiro, R.J.: Editora Vozes.

Bourassa, S. C. (1988). Toward a theory of landscape aesthetics. Landscape and Urban Planning, 15(3-4), 241-252. doi: 10.1016/01692046(88)90048-5

Bourassa, S. C. (1990). A paradigm for landscape aesthetics. Environment and Behavior, 22(6), 787-812. doi: $10.1177 / 0013916590226004$

Bringslimark, T., Hartig, T., \& Patil, G. G. (2009). The psychological benefits of indoor plants: A critical review of the experimental literature. Journal of Environmental Psychology, 29(4), 422-433. doi: 10.1016/j.jenvp.2009.05.001

Buijs, A. E., Elands, B. H. M., \& Langers, F. (2009). No wilderness for immigrants: Cultural differences in images of nature and landscape preferences. Landscape and Urban Planning, 91(3), 113-123. doi: 10.1016/j.landurbplan.2008.12.003 
Caldas Aulete. (n.d.). Disponível em:

http://aulete.uol.com.br/site.php?mdl=aulete_digital. Acesso em: 15/06/2013.

Castro, P. (2005). Crenças e atitudes em relação ao ambiente e à Natureza. In L. Soczka (Ed.), Contextos humanos e psicologia ambiental (pp. 169 - 202). Lisboa: Fundação Calouste Gulbenkain.

Coelho, J. A. P. d. M., Gouveia, V. V., \& Milfont, T. L. (2006). Valores humanos como explicadores de atitudes ambientais e intenção de comportamento pró-ambiental. Psicologia em Estudo, 11(1), 199-207.

de Groot, J. I. M., \& Steg, L. (2010). Relationships between value orientations, self-determined motivational types and pro-environmental behavioural intentions. Journal of Environmental Psychology, 30(4), 368378.

de Kort, Y. A. W., Meijnders, A. L., Sponselee, A. A. G., \& ljsselsteijn, W. A. (2006). What's wrong with virtual trees? Restoring from stress in a mediated environment. Journal of Environmental Psychology, 26(4), 309320.

Despres, C. (1991). The meaning of home: Literature review and directions for future research and theoretical development. Journal of Architecture and Planning Research in Organizational Behavior, 8(2), 96111.

Gressler, S. C., \& Günther, I. d. A. (2013). Ambientes restauradores: definição, histórico, abordagens e pesquisas. Estudos de Psicologia (Natal), 18, 487-495.

Hartig, T. (1993). Nature experience in transactional perspective. Landscape and Urban Planning, 25(1-2), 17-36. doi: 10.1016/01692046(93)90120-3

Joye, Y., \& Van den Berg, A. E. (2012). Restorative environments. In L. Steg, A. E. Van den Berg \& J. I. M. De Groot (Eds.), Environmental psychology- an introduction (pp. 57-66): BPS Blackwell.

Kahn, P. H. (1997). Developmental psychology and the biophilia hypothesis: Children's affiliation with nature. Developmental Review, $17(1), 1-61$.

Kaplan, R. (1983). The role of nature in the urban context. In I. Altman \& J. F. Wohlwill (Eds.), Behavior and the natural environment (Vol. 6, pp. 127-159). New York and London: Plenum Press. 
Karp, D. G. (1996). Values and their effect on pro-environmental behavior. Environment and Behavior, 28(1), 111-133. doi: $10.1177 / 0013916596281006$

Kellert, S. R. (1993). The Biological basis for human values of nature. In S. R. Kellert \& E. O. Wilson (Eds.), The Biophilia Hypothesis (pp. 42-69). Washington, D.C.: Island Press.

Lima, L. P. d. (2006). Atitudes: Estrutura e Mudança. In J. Vala \& M. B. Monteiro (Eds.), Psicologia Social (pp. 187-226). Lisboa: Fundação Calouste Gulbenkian.

Milfont, T. L. (2007). Psychology of environmental attitudes: A crosscultural study of their content and structure. (Unpublished doctoral dissertation), University of Auckland, Auckland, New Zealand. Retrieved from http://www.milfont.com/pubs_nz.php

Rapoport, A. (1969). House Form and Culture. Englewood Cliffs, NJ: Prentice-Hall.

Schultz, P. W. (2002). Inclusion with nature: The psychology of humannature relations. In P. Schmuck \& P. W. Schultz (Eds.), The psychology of sustainable development (pp. 61-78). New York: Kluwer.

Schwarz, B., Mauksch, R., \& Rawls, S. (1995). Housing and the environmental social sciences. In R. Brent \& B. Schwarz (Eds.), Popular American Housing: A Reference Guide (pp. 73-114). Westport, CT: Greenwood Publishing.

Sommer, R. (1973). Espaço pessoal: as bases comportamentais de projetos e planejamentos. São Paulo: EPU Ed. da Universidade de São Paulo.

Speller, G. M. (2005). A importância da Vinculação ao Lugar. In L. Soczka (Ed.), Contextos Humanos e Psicologia Ambiental (pp. 133 168). Lisboa: Fundação Calouste Gulbenkian.

Steg, L., Dreijerink, L., \& Abrahamse, W. (2005). Factors influencing the acceptability of energy policies: A test of VBN theory. Journal of Environmental Psychology, 25(4), 415-425. doi: 10.1016/j.jenvp.2005.08.003

Stern, P. C. (2000). Toward a coherent theory of environmentally significant behavior. Journal of Social Issues, 56(3), 407-424. doi: 10.1111/0022-4537.00175

Stern, P. C., Dietz, T., Abel, T., Guagnano, G. A., \& Kalof, L. (1999). A Value-belief-norm theory of support for social movements: The case of environmentalism. Human Ecology Review, 6(2), 81-95. 
Thompson, S. C. G., \& Barton, M. A. (1994). Ecocentric and anthropocentric attitudes toward the environment. Journal of Environmental Psychology, 14(2), 149-157.

Ulrich, R. S. (1983). Aesthetic and affective response to natural environment. In I. Altman \& J. F. Wohlwill (Eds.), Behavior and the Natural Environment (Vol. 06, pp. 85 - 120). New York: Plenum Press. Ulrich, R. S. (1984). View through a window may influence recovery from surgery. Science, 224(4647), 420-421.

Ulrich, R. S., Simons, R. F., Losito, B. D., Fiorito, E., Miles, M. A., \& Zelson, M. (1991). Stress recovery during exposure to natural and urban environments. Journal of Environmental Psychology, 11(3), 201-230.

United Nations, D. E. S. A. (Producer). (2008, 15/05/2009). Shifting populations. DESA News. vol. 12, n 04, abril 2008. Retrieved from http://www.un.org/esa/desa/desaNews/v12n04/feature.html

van den Berg, A. E. (1999). Individual differences in the aesthetic evaluation of natural landscapes. (Doctor), Rijksuniversiteit Groningen, Groningen.

Wilson, E. O. (1984). Biophilia: Harvard University Press. 